\title{
The case of drug causation of childhood asthma: antibiotics and paracetamol
}

\author{
Konrad Heintze $\cdot$ Karl-Uwe Petersen
}

Received: 5 October 2012 / Accepted: 27 November 2012 /Published online: 5 January 2013

(C) The Author(s) 2012. This article is published with open access at Springerlink.com

\begin{abstract}
Aim The rising prevalence of bronchial asthma has led to world-wide efforts to understand and stem this development. Cross-sectional studies appear to show that early childhood use of antibiotics may be an important contributory factor, with paracetamol as an additional suspected cause. However, mounting evidence, which is reviewed here, points to various confounding factors as the major reasons for these reported associations.

Methods PubMed and EMBASE were systematically searched for studies on associations between antibiotics and/or paracetamol with asthma and/or wheezing, published up to November 2012. A total of 64 pertinent studies were identified, 35 focusing on antibiotics, 19 on paracetamol, and ten addressing both antibiotics and paracetamol, bringing the number of relevant datasets to 74 .

Results Numerous studies were cross-sectional and made no adjustment for the indication of antibiotics or paracetamol; consequently, they were unable to dismiss possible confounding by indication. Where such adjustments could be performed (mostly in longitudinal studies), they substantially weakened or entirely eliminated the association with asthma or asthma surrogates present in the unadjusted data. Conclusion The weight of evidence of the collected studies in our review strongly suggests that the association of antibiotics with childhood asthma reflects various forms of bias, the most prominent of which is confounding by indication. Recent studies and meta-analyses support the same conclusion for
\end{abstract}

Electronic supplementary material The online version of this article (doi:10.1007/s00228-012-1463-7) contains supplementary material, which is available to authorized users.

\section{K. Heintze}

RWTH Aachen University, Aachen, Germany

K.-U. Petersen $(\square)$

Institute of Pharmacology and Toxicology, RWTH Aachen

University, 52072 Aachen, Germany

e-mail: karluwe.petersen@post.rwth-aachen.de paracetamol. Truly indicated antibiotics should not be withheld from infants or young children for fears they might develop asthma. Likewise, there is no sound reason to replace paracetamol as the preferred pain relief and fever medication in this age group.

Keywords Antibiotics · Paracetamol - Acetaminophen . Childhood asthma $\cdot$ Wheeze $\cdot$ Epidemiologic studies

\section{Introduction}

The highly complex pathogenesis of bronchial asthma leaves little room for simple answers and remedies. This setting has led to the formulation of hypotheses aimed at providing straightforward explanations and may explain the eager acceptance of results from numerous, mostly cross-sectional studies postulating causative roles for medications, such as antibiotics and paracetamol, used in pregnancy or early childhood. The nature of the factors involved in bronchial asthma -a disease of worldwide importance, possibly linked to drugs with universally high exposure levels - makes such a possibility highly intriguing, and if true would call for clear consequences. It is the scope of this review to appraise the available evidence. As the abundance of reiterative publications has a propensity to obscure the general picture and possibly impede the identification of higher quality studies, we have undertaken a comprehensive appraisal following predefined rules, with the view to structuring the published work according to the level of evidence. Further, the wealth of dedicated work and publications made it advisable to narrow the focus to exposure in early childhood.

\section{Methods}

PubMed and EMBASE were searched up to 1 November 2012 using two different sets of terms: (1) (antibiotic or 
antibact) and (asthma or wheez) and (children or childhood) and (study or trial); (2) (paracetamol or acetaminophen) and (asthma or wheez) and (children or childhood), and (study or trial). Twenty-six additional studies were found by searching reference lists of relevant articles.

In total, 1,288 papers were found. In the first assessment round, guidelines, review articles, letters and comments, and duplicated publications/listings were discarded, as well as non-English articles and papers addressing conditions other than asthma or wheeze or focusing on management rather than risk factors (Fig. 1). In a second assessment round of 'finetuning', duplicated or interim publications and papers studying the effects of pregnancy rather than childhood exposure, lacking differentiation between adults and children, addressing conditions other than asthma or wheeze, analyzing sales rather than individual drug intake, or focusing on transient wheeze only were discarded. This left 64 studies for consideration, among which ten studies reported on both antibiotics and paracetamol (Fig. 1). Of the numerous birth cohort studies, those including cases after the incident were classified as retrospective, while those identifying cases after recruitment were considered to be prospective.

Of the outcome parameters and results, only wheeze and asthma were considered and listed. While other outcomes, such as eczema and allergic disposition, were studied and

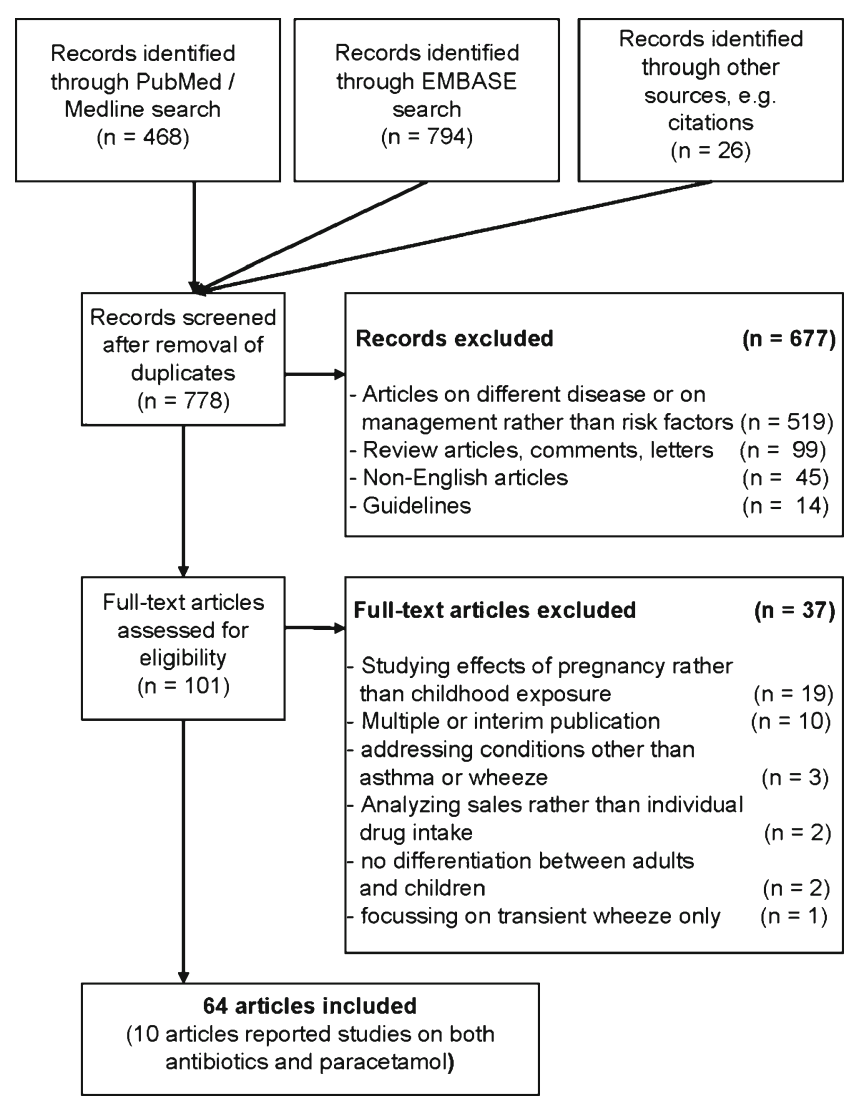

Fig. 1 Study selection for systematic review reported, these might support or speak against associations, but are not decisive for this review.

\section{How to identify asthma in children}

Wheezing alone does not justify a diagnosis of asthma in preschool children. As early as 1995, Martinez and colleagues [1] emphasized that infant wheezing is mostly transient; only in a minority of cases do early wheezing episodes indicate a probability to develop asthma. More recent guidelines and consensus reports [2-4] reflect this view. Wheezing shows a prevalence of almost $50 \%$ in children aged 6 years and is in most cases associated with frequently recurring viral infections of the upper respiratory tract. Thus, even recurrent wheeze is not equivalent to asthma. The majority of participants of the European Respiratory Society task force [4] abstained from using the term asthma to describe preschool wheezing illness. A further uncertainty lies in the understanding and use of the term "wheezing" among parents [3, 4]. Frequently a diagnosis is possible only through long-term follow-up and by observing the child's response to specific treatments [2].

It follows that studies which are based on questionnaires asking parents about wheeze in children of preschool age are of dubious value. This includes the International Study of Asthma andAllergies in Childhood (ISAAC) protocol that was basically laid out in 1995 by Asher [5], a methodology that essentially relies on questionnaires to be completed by adolescents (13-14 years of age) at school, or at home by the parents of children aged 6-7 years. In Phase II, this was supplemented by questionnaires covering suspected risk factors, including drugs (see website for more details: http://isaac.auckland.ac.nz/). Current views hold that parentally reported wheeze should be confirmed by a healthcare professional [3], bearing in mind that not all healthcare workers are equally accurate in estimating the severity of wheeze [4]. Asthmatic disease could be suspected in children with a history of $>3$ episodes of reversible bronchial obstruction documented within the previous 6 months [2]. Also, a history of asthma prescription drugs suggests (but does not prove) that asthma was diagnosed.

\section{Factors that might set the stage for asthma development}

There is a plethora of hazards suspected to promote childhood asthma, including findings in the neonate and parental factors or indicators [6-15]. The notion is evolving that epigenetic changes affecting the developing immune system may be the common pathway to many purported causes $[8$, 16]. Of the invoked postnatal influences, viral infections of the respiratory tract in early life deserve special attention [7, 
$8,17-21]$. Early life in this context denotes infancy, i.e., the period between birth and 2-3 years.

Prospective epidemiologic studies have shown that up to $80 \%$ of asthma exacerbations in children are associated with viral upper respiratory infections [22]. The underlying mechanisms have not been resolved. Alterations of cytokine balance of the infant lung by early respiratory viral infections have been discussed; mediation by epigenetic changes in inflammatory pathways is an attractive-though unproven-hypothesis [16, 20].

Thus, observational studies face the enormous challenge of adjusting for the appropriate confounders, with no guarantee that the identified risk figures are free of residual confounding. Even worse, the accumulated consequences of several unmeasured confounders with small or moderate effects may be able to produce a sizable contortion of the outcome of interest [23]. Integration of many factors leading to increased susceptibility, rather than invocation of a monocausal increase in exposure to one of the classical asthma risk factors, may be required for a full understanding [24].

\section{Antibiotics}

Our literature search on the relationship between antibiotic use in early childhood and later occurrence of asthma equivalents (wheeze) and asthma diagnosis identified 45 studies (Table 1).

\section{Cross-sectional studies}

All 20 cross-sectional studies were integrated into or inspired by ISAAC (Table 1) and reported some forms of association between early use of antibiotics and wheezing and/or asthma. In ten of the studies, a causal association was considered likely; in one case there was no statistically significant association [25]; in two studies the authors avoided making such a conclusion [26] or linked a possible risk to a special disposition [27]; in five reports the association was either not discussed [28, 29], discussed with some scepticism [30,31], or explained by confounding factors [32]; in one study, the association vanished when the odds ratios (OR) were adjusted [33]. Similarly, Wjst et al. [34] considered reverse causation to be the most likely explanation of associations between the use of antibiotics and wheezing/diagnosis of asthma. This conclusion was supported by a substudy in which parents were asked about the indication for use of asthma medication. The association with asthma vanished when only non-pulmonary indications were considered, and the OR for wheeze was substantially reduced.

Two case-control studies nested in birth cohort studies also fall into the category of cross-sectional studies. No clear conclusion on the association with antibiotics was offered by Martel et al. [35], whereas Thomas et al. [36] reported that more cases than controls had received antibiotics during the first year of life and had been prescribed antibiotics for lower respiratory tract infection during the first 3 years of life. Statistical significance was borderline and was found only for prescriptions over the whole 3-year period [OR $1.47,95 \%$ confidence interval (CI) 1.01-2.13]. Conspicuously, no difference was noted in single-year comparisons, including the important period between 0 and 1 year of age.

Longitudinal studies

Markedly different conclusions on antibiotic-induced risk of childhood asthma were drawn by the authors of four retrospective birth cohort studies [37-40], of which the authors of only one study recognized a significant association [37]. The notion arrived at by the authors of the remaining three studies was that the observed associations were best attributed to various kinds of bias. McKeever et al. [38] reported small associations that could largely be explained by consulting behavior. Children with asthma were more likely to have early respiratory tract infections. These authors considered that the association might be more in keeping with reverse than true causation. Two additional studies are illustrated in Fig. 2. Cullinan et al. [39] collected self-reports of asthma and compared them with contemporary medical records. The use of antibiotics in the first 5 years of life was associated with later asthma, but only when antibiotics were prescribed for lower respiratory infections. No association was found with non-respiratory infections. The authors considered reverse causation bias as the most plausible explanation. Almqvist et al. [40] distinguished between antibiotics typically used for airway and non-airway infections. Only the former group was associated with a significant hazard ratio (HR), and the authors concluded that there was reverse causation or confounding by indication due to respiratory tract infections.

Nineteen prospective birth cohort studies were found (Table 1), yielding a similar picture. In five studies, a causal association was suspected. No discrimination between antibiotics could be determined in two of these [41, 42]; in two other studies, associations were found to be limited to certain antibiotic subgroups [43, 44]; in the last study a small risk was concluded by Marra et al. [45], but refuted by the same group in a later study [46].

Two studies reached more or less equivocal conclusions. Mitchell et al. [47] felt that their data strengthened the hypothesis of a causal relationship, but acknowledged the possibility of confounding by indication. In the second further study, the possibilities of causation and of confounding by indication were given similar weights [48].

Various forms of bias strongly arguing against an association were identified in the remaining 12 prospective birth 
Table 1 Studies on the association between early antibiotic exposure and childhood asthma

Reference (Comments)

Cross-sectional Studies

(ISAAC questionnaires, Beasley et al. [77]; involved no adjustment for respiratory infections)

Case-control Studies, Nested in a Birth Cohort Study

\section{Retrospective Birth Cohort} Studies (Cases of interest identified after the incident)

\section{Prospective Birth Cohort} Studies (Cases of interest identified after recruitment)

\section{Causal association considered likely}

Kwon and Lee [78]; Wickens et al. [79]; Awasthi et al. [80] (also acknowledged possibility of various types of bias); Cohet et al. [81]; Ahn et al. [82] (suggested an association with fever, antibiotics, and acute gastroenteritis during infancy); Floistrup et al. [83]; Foliaki et al. [84]; Karimi and Mirzaei [85]; Mitchell et al. [86]; Sobko et al. [25] (small number of cases; no statistical significance of association, only slight association in crude OR); Yeh et al. [87] (associations with respiratory infections and antipyretics (addressed as mostly paracetamol, no quantification) and strong temporal association with kindergarten entry suggest confounding by indication)

\section{No conclusion of causal association}

Von Mutius et al. [26] (discussed various kinds of bias and were cautious to conclude a causative role of antibiotics)

\section{Risk in case of special disposition considered}

Droste et al. [27] (very weak association (OR1.7; CI 1.0-3.1); concluded that antibiotics put those children at risk, who are genetically predisposed to atopic immune responses)

Association reported, rather explained by reverse causation

Wjst et al. [34] (considered reverse causation the most likely possible explanation, but did not exclude true causation; for antibiotic use in non-pulmonary disease, the association vanished for asthma and weakened for wheezing)

Association visible in data, undiscussed

Sharma and Banga [28] (weak association (OR 1.6, CI 1.1-2.1)); Del-Rio-Navarro et al. [29]

No association in adjusted $O R$, undiscussed

Castro-Rodriguez et al. [33]

Association discussed with scepticism

Barragan-Meijueiro et al. [30]; Garcia et al. [31]

Association explained by confounding factors

Rusconi et al. [32]

Association reported, no clear conclusion

Martel et al. [35] (discussed confounding by indication, recall bias, and reverse causation bias as possible confounders)

Causal association considered likely for broad-spectrum antibiotics

Thomas et al. [36] (association weak (OR 1.47, CI 1.01-2.13), low number of cases; reverse causation not excluded)

\section{Concluded a causal association}

Kozyrskvj et al. [37] (antibiotics in the first year of life associated with asthma at 7 years; adjustment for lower respiratory infections reduced the association, restriction to children in an urban environment deleted it for unknown reasons; remaining association weak (OR 1.05, CI 1.02-1.09); confounding by indication remains a possibility)

\section{Association rather explained by confounding factors}

McKeever et al. [38] (small effects, that could be explained to a large extent by consulting behaviour); Cullinan et al. [39] (association confined to lower respiratory infections and not observed in non-respiratory infections; cf. Fig. 2); Almqvist et al. [40] (hazard ratios for typical airway antibiotics much stronger than for non-airway antibiotics; cf. Fig. 2)

\section{Causal association concluded}

Alm et al. [41] (studied age group (until 12 months) does not allow firm conclusions on asthma; no adjustment for respiratory infections, confounding by indication still possible); Risnes et al. [42] (interview 6 years after birth, recall bias possible); Goksör et al. [43] (broad spectrum antibiotics were considered causative, no details; confounding by indication possible due to lack of information on infectious diagnosis); Jedrychowski et al. [44] (when adjusted for respiratory infections, the Odds ratio lost statistical significance; macrolide and cephalosporin associations lost strength, but retained significance; considered that immuno-modulation might underlie asthma promotion by (certain) antibiotics); Marra et al. [45] (after excluding children with upper or lower respiratory infection the hazard ratio still showed a small association between antibiotics and asthma (but cf. Marra et al. [46], below));

\section{Causal association as well as confounding by indication considered}

Mitchell et al. [47] (no adjustment for airway infections; concluded that antibiotics are a risk factor but considered confounding by respiratory infections); Kummeling et al. [48] (no adjustment for airway infections; in a later overview, the same authors suggested confounding by indication (Kummeling and Thijs [66])) 
Table 1 (continued)

Reference (Comments)

\begin{abstract}
Association explained by confounding factors or no associations found
Marra et al. [46] (considered that antibiotics were used for asthmatic wheeze (reverse causation)); Kusel et al. [49] (concluded that the data did not indicate that using antibiotics early in life led to asthma at 5 years; cf. Fig. 2); Celedon et al. [50] (association of antibiotics in the first year of life with asthma persistent at age of 5 years; lost significance after adjustment for lower respiratory infections; concluded that findings do not support association between antibiotic use in early life and childhood asthma; cf. Fig. 2); Mai et al. [51] (concluded that the association could at least partially be explained by early respiratory infection; cf. Fig. 2); Harris et al. [52] (concluded there was no plausible causative relationship with subsequent respiratory allergies including wheeze); Ponsonby et al. [88] (no association between antibiotic use in the first month of life and childhood asthma); Illi et al. [89] (reported lower respiratory tract infections in the first 3 years of life associated with wheeze; no association with antibiotics); Celedon et al. [90] (findings do not support association between antibiotic use in the first year of life and persistent wheezing or asthma at the age of 5); Verhulst et al. [91] (concluded from lack of temporal associations that association between wheezing and antibiotics most likely reflected reverse causation); Wickens et al. [92] (suggested that the effect of antibiotics on respiratory disease may be due to confounding by chest infections); Dom et al. [93] (the association was described as negative, i.e. a protective effect of antibiotics); Su et al. [94] (concluded that at least a major portion of the association may be an artefact of the strong relation of illness visits to a doctor to both antibiotic use and risk for asthma diagnosis)
\end{abstract}

A more detailed and annotated version including patient numbers is given in the Electronic Supplementary Material (Table 3)

cohort studies, or no association was detected at all (Table 1). Of this subset, five studies may serve as instructive examples. Three of these are illustrated in Fig. 2. Adjustment for typical confounding factors [49] or respiratory infections in the history of the patients $[50,51]$ led to sizable to dramatic decreases in the respective OR, which in each case lost their statistical significance. In a study by Illi et al. [56], antibiotics given for lower respiratory tract infections were excluded from the analysis, which probably explains the absence of an association between childhood antibiotics and a later diagnosis of asthma. Finally, Harris et al. [52] tested associations for respiratory and non-respiratory infections separately. All associations observed with early use of antibiotics were weak, and non-respiratory infections associations, slight or borderline, were detected in only two of the six analyzed age brackets (Table 1).

\section{Association between the use of paracetamol in early childhood and development of bronchial asthma}

There are numerous non-randomized studies, both prospective and retrospective, which report findings supporting the notion that exposure to paracetamol in the first years of life, and/or the year preceding data collection, is associated either with diagnoses of asthma at the age of 5-6 years or later, or at least with signs (mainly wheezing), which suggest a propensity for developing adult-type asthma at a later date.

\section{Cross-sectional studies}

Our literature search identified 29 relevant studies. The majority of these (21) are cross-sectional, of which 19 form part of or were designed in keeping with ISAAC
Fig. 2 Influence of data collection and analysis on the association between childhood or adult asthma and the use of antibiotics in early life. Graph is presented as odds ratio $(O R)$ or hazard ratio $(H R)$ values \pm the confidence interval (whiskers). See Table 1 for details on the mentioned studies. adj. for resp. inf. Adjusted for respiratory infections [39, 40, 49-51]

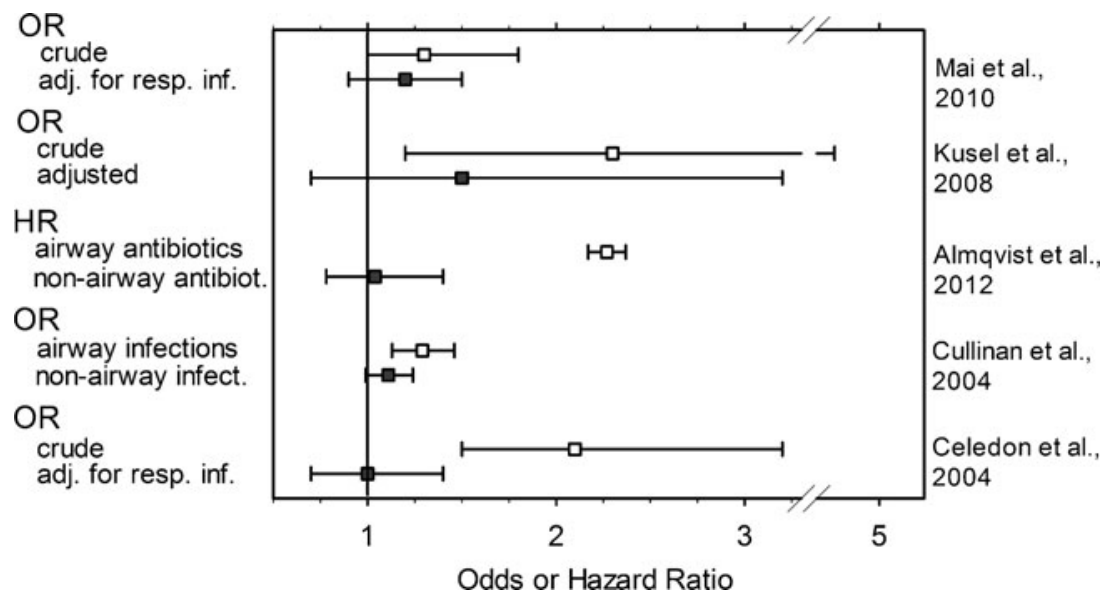


(Table 2). All of these studies reported some form of association. The authors of only two of the ISAAC-type studies seriously questioned the causality of the detected association [28] or concluded a major or decisive role for confounding factors [32]. Of two case-control studies, the authors of one considered sizable contributions by various forms of bias [53], the authors of the second cautioned against distortions by recall bias and reverse causation [54].

\section{Longitudinal studies}

Six prospective birth cohort studies were found. In a first study [55], use of paracetamol was documented until age 7 years. The primary outcome was asthma at 6-7 years; one of the secondary outcomes was infantile wheeze. While the crude data showed that increasing frequency of paracetamol use was weakly associated with an enhanced risk of childhood asthma, this association vanished after adjustment for frequency of respiratory infections (Fig. 3), strongly suggesting that the data were confounded by indication. As predictable for such confounding, use of paracetamol for non-respiratory causes was not associated with asthma [55].

Similar conclusions were drawn by the authors of another prospective population-based birth cohort study [56] investigating the association between febrile illnesses and antipyretic medication during infancy and the later development of allergic disease. There was a clear distinction between respiratory and non-respiratory infections. The number of paracetamol treatment courses for gastroenteritis or urinary tract infections did not differ between asthmatic and non-asthmatic children, contrary to expectations were paracetamol to have a pathogenetic role in asthma. On the other hand, prescriptions for respiratory tract infections were more frequent in asthmatic than in non-

Table 2 Studies on the association between early paracetamol exposure and childhood asthma

\begin{tabular}{|c|c|}
\hline & Reference (Comments) \\
\hline \multirow{6}{*}{$\begin{array}{l}\text { Cross-sectional Studies } \\
\text { (ISAAC questionnaires, } \\
\text { Beasley et al. [77]; involved no } \\
\text { adjustment for respiratory } \\
\text { infections) }\end{array}$} & Causal association considered likely \\
\hline & $\begin{array}{l}\text { Del-Rio-Navarro et al. [29]; Barragan-Meijueiro et al. [30]; Garcia et al. [31]; Beasley et al. [77]; Cohet et al. } \\
\text { [81]; Floistrup et al. [83] (antipyretics in the first year of life associated with diagnosis of asthma, very slight } \\
\text { association (OR 1.23, CI 1.01-1.51), studied antipyretics, with no distinction between individual drugs; no } \\
\text { association with later use); Mitchell et al. [86]; Yeh et al. [87] (association with antipyretics (addressed as } \\
\text { mostly paracetamol, no quantification); associations with antibiotics and respiratory infections and a strong } \\
\text { temporal association with kindergarten entry suggest confounding by indication); Karimi et al. [95] (where } \\
\text { present, associations where borderline); Kuschnir and Alves de Cunha [96]; Vlaski et al. [97]; Wong et al. } \\
\text { [98]; Foliaki et al. [99] (association with asthma ever very slight (OR 1.16, CI 1.00-1.35); Wang et al. [100]; } \\
\text { Beasley et al. [101]; Gonzalez-Barcala et al. [102] }\end{array}$ \\
\hline & Association visible in data, undiscussed \\
\hline & Castro-Rodriguez et al. [33] \\
\hline & Association explained by confounding factors \\
\hline & Rusconi et al. [32]; Sharma and Banga [28] \\
\hline \multirow{2}{*}{$\begin{array}{l}\text { Further Cross-sectional Studies, } \\
\text { Case-control Design }\end{array}$} & Association discussed with scepticism \\
\hline & Koniman et al. [53]; Rodriguez Martinez et al. [54] \\
\hline \multirow{6}{*}{$\begin{array}{l}\text { Prospective Birth Cohort Studies } \\
\text { (Cases of interest identified after } \\
\text { recruitment) }\end{array}$} & Causal association considered likely \\
\hline & $\begin{array}{l}\text { Amberbir et al. [60] (studied age group does not allow firm conclusions on asthma; adjustment for respiratory } \\
\text { infections hinges on correct recall of symptoms, still leaving the possibility of confounding by indication } \\
\text { and recall bias) }\end{array}$ \\
\hline & Causal association as well as confounding considered \\
\hline & $\begin{array}{l}\text { Bakkeheim et al. [59] (considered reverse causation a possibility because of paracetamol's association with } \\
\text { history of, but not with, current asthma; association found only after adjusting for gender (girls, not boys)); } \\
\text { Wickens et al. [61] (ISAAC questionnaire; considered a possible causal relationship, but also contributions } \\
\text { by recall bias, reverse causation, and confounding by viral respiratory infections; adjustment for chest } \\
\text { infections did not cover the critical period of infancy) }\end{array}$ \\
\hline & Association explained by confounding factors or no associations found \\
\hline & Lowe et al. [55]; Schnabel et al. [56]; Shaheen et al. [58] \\
\hline \multirow[t]{2}{*}{ Prospective Studies } & No risk of hospitalization or equivocal outcome \\
\hline & $\begin{array}{l}\text { Lesko and Mitchell [63] (antipyretics not associated with risk of hospitalization for asthma/bronchiolitis); } \\
\text { Lesko et al. [64] (compared paracetamol with ibuprofen; differences might be due to an increased risk after } \\
\text { paracetamol or a decrease after ibuprofen) }\end{array}$ \\
\hline
\end{tabular}

A more detailed and annotated version including patient numbers is given in the Electronic Supplementary Material (Table 4) 
Fig. 3 Influence of data collection and analysis on the association between childhood asthma and use of paracetamol in early life. Data are presented as OR values (squares) $\pm \mathrm{CI}$ (whiskers). See Table 2 for study details. inf. Infancy $[55,58]$

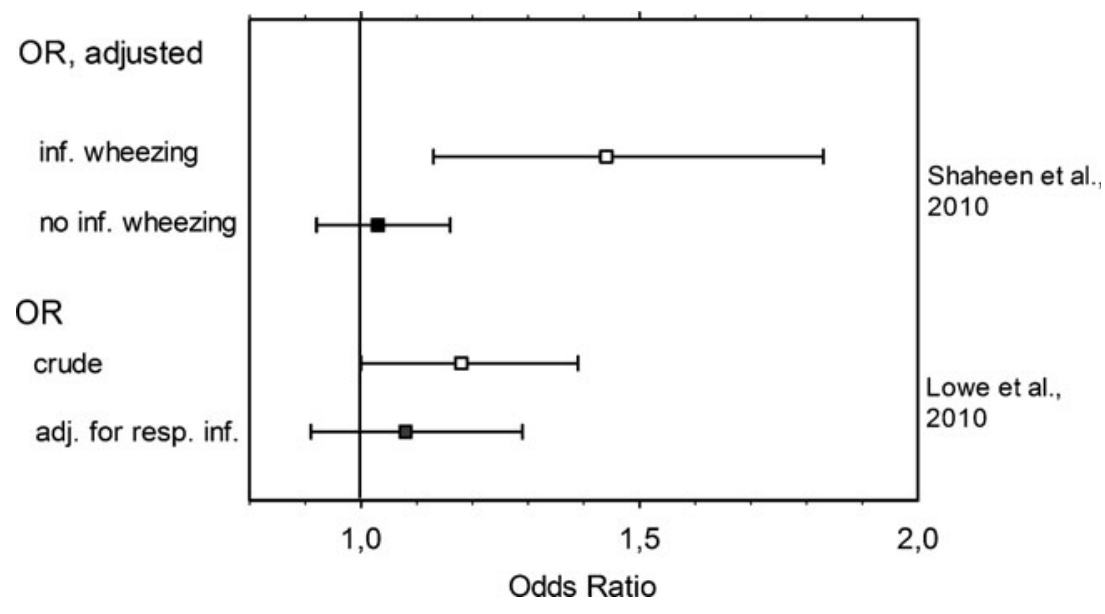

At odds with these studies are the results of the investigation by Amberbir et al. [60] who used data from a population-based cohort in Ethiopia, followed from pregnancy to the age of 3 years. Symptoms of respiratory infection were surveyed at 2 months and 1 year. According to the completed ISAAC questionnaires, use of paracetamol in the first year of life was associated with the incidence of wheeze, but also with symptoms of respiratory infections. Adjustment for such symptoms only slightly reduced the strength of the association. The authors concluded an association between infantile use of paracetamol and an increased risk of incidence of wheeze. It should be noted that wheezing at 3 years is no safe predictor of later asthma. Given the technical difficulties of that study, factors such as recall and misclassification bias or confounding by indication can probably not be dismissed.

Finally, ambivalent signals come from the study by Wickens et al. [61]. Due to the use of ISAAC questionnaires the indications for paracetamol use remain unknown in this study. For asthma and wheeze at 6 years, an association was obtained for use of paracetamol between 5 and 6 years of age ( $>19$ times), but not for early use. For less frequent use between 5 and 6 years of age (3-10 times), an association was found for wheeze, not for asthma; adjustment in a subgroup for chest infections in the period between age 5 and 6 years weakened but did not dissipate the association. However, as this adjustment did not cover the critical period of infancy (i.e., between birth and 2 or 3 years), it is not sufficient to dismiss a role for confounding by indication. The authors presented an equivocal discussion considering a causal relationship as well as a role for recall bias, reverse causation, and confounding by viral respiratory infections. Thus, while cross-sectional studies on the pathogenesis of juvenile asthma would suggest a risk of using paracetamol in early childhood, such risk disappears or is hardly discernible in the majority of longitudinal studies. This notion is also supported by a birth cohort study $(n=2,091)$ that has been published in abstract form [62] and hence not been 
integrated in Table 2. A sizable association between frequent paracetamol use at the age of 4 years and wheeze at 6 years in the Leicester Respiratory Cohorts was evident in the crude data, but entirely disappeared after adjustment, among others for respiratory symptoms. The authors suggested that the association could be totally explained by confounding.

\section{Randomized studies}

In a large double blind trial, children in need of antipyretic treatment, including $47 \%$ with a respiratory infection, were randomized to receive paracetamol or ibuprofen and followed up for hospitalization under a specific diagnosis. There was no difference between the two drugs in terms of hospitalization for bronchiolitis or asthma during the 4-week follow-up period [63]. Using a very similar design, the same group later studied asthmatic children with febrile disease [64]. Again, hospitalization for asthma was not different between the paracetamol and ibuprofen groups. However, outpatient visits for asthma were more frequent if paracetamol was used for antipyretic treatment during respiratory infections, but there was no difference for other causes of fever. The authors concluded that either paracetamol caused asthmatic symptoms or ibuprofen afforded protection. The latter alternative would be more appealing, as harmful effects of paracetamol should not have spared patients with non-respiratory causes of fever. The short duration of the study would call for confirmation over longer periods.

\section{Discussion}

The 64 studies considered in this review embrace a large number of cross-sectional reports, which, mostly relying on the unmodified ISAAC questionnaires, keep being published at a steady rate and attract attention, even though their shortcomings were recognized early.

Despite the increase in knowledge achieved with the ISAAC methodology, the use of uniform questionnaires has also perpetuated basic shortcomings. With regard to antibiotics (and paracetamol, see below), the lack of regard for the treated disorder is most conspicuous. This is important, as the typical indication for the use of antibiotics in children is fever, frequently caused by respiratory infections; it seems reasonable to assume that antibiotics are often administered even though the airway infection is of viral origin. Thus, any identified association with antibiotics is at risk of confounding by indication (the putative cause and effect items are caused by a third event), for which adjustment is impossible owing to a lack of information. Other obvious sources of bias, typical of cross-sectional studies, are recall bias (faulty recollection of past events), misclassification bias (disagreeing views on the nature of wheezing and asthma; in some studies mitigated by video questionnaires), and reverse causation (the temporal order of events is unclear, so that any putative cause of asthmatic disease may rather be its consequence).

For good reasons, cross-sectional studies are considered less conclusive and were consistently excluded from analysis in a recent review [65]. We decided that presenting and evaluating such studies was the preferable approach to simply neglecting them. This broad approach also provided what may be considered a strength of the present overview, namely, a comprehensive appreciation and appraisal of individual publications.

Early childhood antibiotics as a cause for asthma

The hypothesis of antibiotic-induced childhood asthma has been debated since the late 1990s, and several pathomechanisms have been invoked. However, this discussion may be futile, considering the growing consensus that such apparent associations are mainly due to confounding factors, especially, as reviewed by Kummeling and Thijs [66], in the form of recall bias and confounding by indication. The same group has recently refined their review in a metaanalysis [65]. Eighteen studies qualified for the overall meta-analysis. The pooled risk estimate yielded an OR of 1.27 (CI 1.12-1.43), indicating a slight increase in the risk of developing asthma and/or wheeze after antibiotic use in the first year of life. Nine of these studies displayed no overlap between the exposure to antibiotics and the development of first wheezing/asthmatic symptoms in the statistical analysis (avoidance of recall bias) and, secondly, presented OR values adjusted for lower respiratory tract infections (avoidance of confounding by indication). In this subset, the pooled OR was 1.12 (CI $0.98-1.26$ ), with the lower $95 \%$ CI of 0.98 indicating that an OR of 1.0 cannot be excluded with certainty [65].

The authors of a concurrent systematic review [67] arrived at similar conclusions. Five non-retrospective studies, which were attributed the greatest validity because of adjustment for respiratory infection, yielded a pooled OR of 1.13 (CI 1.10-1.17), suggesting a significant but weak association between antibiotic use in early life and childhood asthma. The discrepancy between this appraisal and that of Penders et al. [65] can be explained by the fact that the latter authors [65] included four additional relevant studies, the majority of which refuted an association between early use of antibiotics and childhood asthma.

In line with previous reviews $[67,68]$, the present overview shows that the evidence to support a role for antibiotics in the development of childhood asthma mostly derives from cross-sectional studies, whereas prospective studies find no or only weak associations. 
Popular arguments supporting a causation of childhood asthma by paracetamol

The argumentative basis for a causal role of early childhood use of paracetamol in asthma development has recently been summarized [69] (cited in italics below), allowing a pointby-point inspection of its soundness.

1) The strength of the association. The use of this term implies that absolute values can denote stronger and weaker associations. OR of $<2$ are perceived as small. The authors of only four of the 19 cross-sectional studies in Table 2 arrived at OR of $>2$, and two further studies, dependent on the studied topic, reported values of $<2$ and $>2$, respectively. Thus, overall, the strength of the association cannot be considered large.

2) The consistency of the association across age, geography, and culture. The authors of the cross-sectional studies of Table 2 agree that a certain level of confounding cannot be dismissed in their results. Clearly, factors such as confounding by indication and recall bias will show consistency across age, geography and culture.

3) The dose-response relationship. Confounding by indication will show such a relationship: more severe airway infections will cause more febrile days. It is selfevident that more severe febrile illness will prompt a larger consumption of paracetamol.

4) The timing of increased acetaminophen use and the asthma epidemic. Coincidence is not causality. In a recent analysis of the "asthma epidemic," the authors concluded that gene-environment interactions probably involved in the development of asthma include exposure to animals, endotoxins, tobacco smoke, viruses, ozone, and day-care, among others; no mention was made of paracetamol [70].

5) The relationship between per-capita sales of acetaminophen and asthma prevalence across countries. As reported in the original study [71], there was a clear dichotomy between anglophone and other countries, the former being responsible for the bulk of the associations. After controlling for the "anglophone" effect, the reported associations were greatly attenuated or abolished, and most (including asthma and wheeze) became non-significant. Thus, there is certainly no association "across countries" and the argument that "prevalence of childhood wheezing in 36 countries...is predicted by each country's per-capita sales of acetaminophen" [69] is a misrepresentation of the data.

6) The results of a double-blind trial of ibuprofen and acetaminophen for treatment of fever in asthmatic children. This trial [64] has been discussed above. When antipyretics were used for febrile respiratory infections, paracetamol was associated with more frequent outpatient visits for asthma than ibuprofen, whereas no such difference was seen when other causes of fever were the indication. Thus, these results do not support a role for paracetamol in pathogenesis of asthma.

7) The biologically plausible mechanism of glutathione depletion in airway mucosa. Used as a constant topic throughout the literature, this argument essentially rests on two publications. In one study [72], human alveolar macrophages and type II pneumocytes were exposed in vitro to paracetamol concentrations ranging from 0.05 to $1 \mathrm{mM}$ (7.6- to $151 \mathrm{mg} / \mathrm{l})$. At $0.1 \mathrm{mM}$ (15.1 mg/l, which approximates typical maximal plasma concentrations in humans), a 4-h incubation caused decreases in intracellular glutathione levels by approximately $30 \%$ (read from original figure) or $20 \%$ (indicated in the text). Similarly, daily doses of $4 \times 1 \mathrm{~g}$ paracetamol, administered for 14 days to human volunteers, caused reductions in antioxidant capacity of the blood, which was interpreted as a reduction in glutathione concentrations. The largest decrease amounted to $25 \%$. While these observations are frequently viewed as indicative of a potential to cause lung injury, their quantitative relevance is questionable. As discussed by others [73], plasma concentrations of glutathione display a diurnal rhythm, with meal-dependent increases, which span a $21 \%$ interval between minimal and maximal concentrations (1.1 and 1.4 $\mu \mathrm{M}$, read from figure) [74]. Thus, as fasting is not considered damaging to lung tissue, the relevance of glutathione depletion by paracetamol to possible lung injurious actions remains to be shown.

Antibiotics and paracetamol as asthma promoters: comparable patterns

There are striking similarities between the two therapeutic modalities that have been put forward as contributors to the rising prevalence of childhood asthma. Both antibiotics and paracetamol are frequently administered to treat febrile disease, and as respiratory infections account for a great deal of such disorders in infancy and childhood, (co-)prescriptions for

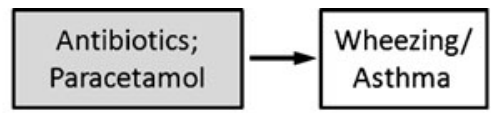

Time

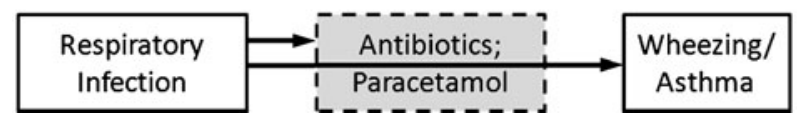

Fig. 4 Confounding by indication. In principle, an association between the use of antibiotics or paracetamol and later wheezing or bronchial asthma could be explained by direct causality or by a third factor (respiratory infection) prompting prescription of antibiotics and/ or paracetamol and at the same time laying the ground for later wheezing/asthma 
airway infections are common. At the same time, viral, but also bacterial respiratory infections are known to set the stage for asthma development. In hindsight, it has been inevitable that the flood of cross-sectional studies (22 on antibiotics and 21 on paracetamol in this overview) would detect associations between these drugs and asthma or asthma equivalents. As most of these surveys adhered to the ISAAC strategy and hence failed to seek information about the reason for the drug prescription, there was no way to adjust for airway infections and hence no possibility to avoid confounding by indication (see Fig. 4). Nonetheless, with only few exceptions, the authors suggested causative associations, admitted but downplayed possible bias, cited plausible pathomechanisms, and called for controlled studies.

While controlled studies are not available, the results from properly designed longitudinal cohort studies, although not randomized, shed more light on possible confounders. We have evaluated 29 such studies, including 25 prospective birth cohort studies. In 12 of 19 prospective studies with antibiotics, the authors concluded that distortion by confounding factors explained most or all of the associations. There were six dissenting studies [41-45], and with respect to one of these, the authors reached the opposite conclusion on a later occasion [46]. Moreover, Mitchell et al. [47], while seeing the case for an antibiotic causation strengthened, acknowledged the possibility of confounding by indication. The authors of the remaining study [48] considered both bias and true causation possible, but suggested confounding by indication in a later overview [66].

Likewise, the authors of three of the six prospective birth cohort studies on paracetamol concluded either a causative role for paracetamol [60] or considered it possible with different levels of caution $[59,61]$. The authors of the three remaining studies $[55,56,58]$ reasoned that associations were essentially due to bias.

\section{Conclusion}

There is growing consensus that the hypothesis of early use of antibiotics promoting asthma in children and adolescents is unproven and false. The striking consistency between antibiotics and paracetamol in these associations strongly argues that a causative role for paracetamol is also much less relevant than the results of cross-sectional studies would suggest. That apparent associations are more likely explained by confounding by indication is also the conclusion drawn by the authors of a recent commentary [75], referring to possible lessons from the antibiotic hypothesis. A concise summary has been provided by the European Medicines Agency's Pharmacoviligance Working Party [76] in its recent statement that available evidence does not support a causal relationship between paracetamol and asthma in children after exposure in early infancy.
Conflicts of interest $\mathrm{KH}$ and KUP have acted as expert advisers to bene-Arzneimitttel and Boehringer Ingelheim Pharma on paracetamol risk evaluation. KUP was an advisor to the Expert Advisory Committee for Prescription-Only Issues of the Federal Institute for Drugs and Medical Devices, Germany.

Open Access This article is distributed under the terms of the Creative Commons Attribution License which permits any use, distribution, and reproduction in any medium, provided the original author(s) and the source are credited.

\section{References}

1. Martinez FD, Wright AL, Taussig LM, Holberg CJ, Halonen M et al (1995) Asthma and wheezing in the first six years of life. The Group Health Medical Associates. N Engl J Med 332(3):133138. doi:10.1056/NEJM199501193320301

2. Bacharier LB, Boner A, Carlsen KH, Eigenmann PA, Frischer T et al (2008) Diagnosis and treatment of asthma in childhood: a PRACTALL consensus report. Allergy 63(1):5-34. doi:10.1111/ j.1398-9995.2007.01586.x

3. Brand P (2008) New guidelines on recurrent wheeze in preschool children: implications for primary care. Prim Care Respir J 17 (4):243-245. doi:10.3132/pcrj.2008.00069

4. Brand PL, Baraldi E, Bisgaard H, Boner AL, Castro-Rodriguez JA et al (2008) Definition, assessment and treatment of wheezing disorders in preschool children: an evidence-based approach. Eur Respir J 32(4):1096-1110. doi:10.1183/09031936.00002108

5. Asher MI, Keil U, Anderson HR, Beasley R, Crane J et al (1995) International Study of Asthma and Allergies in Childhood (ISAAC): rationale and methods. Eur Respir J 8(3):483-491

6. Algert CS, Bowen JR, Lain SL, Allen HD, Vivian-Taylor JM et al (2011) Pregnancy exposures and risk of childhood asthma admission in a population birth cohort. Pediatr Allergy Immunol 22 (8):836-842. doi:10.1111/j.1399-3038.2011.01206.x

7. Arshad SH, Kurukulaaratchy RJ, Fenn M, Matthews S (2005) Early life risk factors for current wheeze, asthma, and bronchial hyperresponsiveness at 10 years of age. Chest 127(2):502-508. doi:10.1378/chest.127.2.502

8. Duijts L (2012) Fetal and infant origins of asthma. Eur J Epidemiol 27(1):5-14. doi:10.1007/s10654-012-9657-y

9. Bisgaard H, Loland L, Holst KK, Pipper CB (2009) Prenatal determinants of neonatal lung function in high-risk newborns. $\mathrm{J}$ Allergy Clin Immunol 123(3):651-657. doi:10.1016/ j.jaci.2008.11.036, 657 e651-654

10. Getahun D, Strickland D, Zeiger RS, Fassett MJ, Chen W et al (2010) Effect of chorioamnionitis on early childhood asthma. Arch Pediatr Adolesc Med 164(2):187-192. doi:10.1001/ archpediatrics.2009.238

11. Kumar R, Yu Y, Story RE, Pongracic JA, Gupta R et al (2008) Prematurity, chorioamnionitis, and the development of recurrent wheezing: a prospective birth cohort study. J Allergy Clin Immunol 121(4):878 e876-884 e876. doi:10.1016/j.jaci.2008.01.030

12. McKeever TM, Lewis SA, Smith C, Hubbard R (2002) The importance of prenatal exposures on the development of allergic disease: a birth cohort study using the West Midlands General Practice Database. Am J Respir Crit Care Med 166(6):827-832

13. Reyes M, Perzanowski MS, Whyatt RM, Kelvin EA, Rundle AG et al (2011) Relationship between maternal demoralization, wheeze, and immunoglobulin E among inner-city children. Ann Allergy Asthma Immunol 107(1):42 e41-49 e41. doi:10.1016/ j.anai.2011.03.004

14. Sevelsted A, Bisgaard H (2012) Neonatal size in term children is associated with asthma at age 7 , but not with atopic dermatitis or 
allergic sensitization. Allergy 67(5):670-675. doi:10.1111/ j.1398-9995.2012.02805.x

15. Tedner SG, Örtqvist AK, Almqvist C (2012) Fetal growth and risk of childhood asthma and allergic disease. doi:10.1111/j.13652222.2012.03997.x

16. Martino D, Prescott S (2011) Epigenetics and prenatal influences on asthma and allergic airways disease. Chest 139(3):640-647. doi: $10.1378 /$ chest. $10-1800$

17. Asher MI (2010) Recent perspectives on global epidemiology of asthma in childhood. Allergol Immunopathol (Madr) 38(2):8387. doi:10.1016/j.aller.2009.11.002

18. Visser CA, Garcia-Marcos L, Eggink J, Brand PL (2010) Prevalence and risk factors of wheeze in Dutch infants in their first year of life. Pediatr Pulmonol 45(2):149-156. doi:10.1002/ppul.21161

19. Busse WW, Lemanske RF Jr, Gern JE (2010) Role of viral respiratory infections in asthma and asthma exacerbations. Lancet 376(9743):826-834. doi:10.1016/S0140-6736(10)61380-3

20. Tregoning JS, Schwarze J (2010) Respiratory viral infections in infants: causes, clinical symptoms, virology, and immunology. Clin Microbiol Rev 23(1):74-98. doi:10.1128/CMR.00032-09

21. Holt PG, Strickland DH, Sly PD (2012) Virus infection and allergy in the development of asthma: what is the connection? Curr Opin Allergy Clin Immunol 12(2):151-157. doi:10.1097/ ACI.0b013e3283520166

22. Johnston SL, Pattemore PK, Sanderson G, Smith S, Lampe F et al (1995) Community study of role of viral infections in exacerbations of asthma in 9-11 year old children. Br Med J 310(6989):1225-1229

23. Fewell Z, Davey Smith G, Sterne JA (2007) The impact of residual and unmeasured confounding in epidemiologic studies: a simulation study. Am J Epidemiol 166(6):646-655. doi:10.1093/aje/kwm165

24. Wong GW, von Mutius E, Douwes J, Pearce N (2006) Environmental determinants associated with the development of asthma in childhood. Int J Tuberc Lung Dis 10(3):242-251

25. Sobko T, Schiött J, Ehlin A, Lundberg J, Montgomery S et al (2010) Neonatal sepsis, antibiotic therapy and later risk of asthma and allergy. Paediatr Perinat Epidemiol 24(1):88-92

26. von Mutius E, Illi S, Hirsch T, Leupold W, Keil U et al (1999) Frequency of infections and risk of asthma, atopy and airway hyperresponsiveness in children. Eur Respir J 14(1):4-11

27. Droste JH, Wieringa MH, Weyler JJ, Nelen VJ, Vermeire PA et al (2000) Does the use of antibiotics in early childhood increase the risk of asthma and allergic disease? Clin Exp Allergy 30(11):1547-1553

28. Sharma SK, Banga A (2007) Prevalence and risk factors for wheezing in children from rural areas of north India. Allergy Asthma Proc 28(6):647-653. doi:10.2500/aap.2007.28.3059

29. Del-Rio-Navarro BE, Ito-Tsuchiya FM, Berber A, Zepeda-Ortega B, Sienra-Monge JJ et al (2008) Study of the relationship between acetaminophen and asthma in Mexican children aged 6 to 7 years in 3 Mexican cities using ISAAC methodology. J Investig Allergol Clin Immunol 18(3):194-201

30. Barragan-Meijueiro MM, Morfin-Maciel B, Nava-Ocampo AA (2006) A Mexican population-based study on exposure to paracetamol and the risk of wheezing, rhinitis, and eeczema in childhood. J Investig Allergol Clin Immunol 16(4):247-252

31. Garcia E, Aristizabal G, Vasquez C, Rodriguez-Martinez CE, Sarmiento OL et al (2008) Prevalence of and factors associated with current asthma symptoms in school children aged 6-7 and 13-14 yr old in Bogota, Colombia. Pediatr Allergy Immunol 19 (4):307-314. doi:10.1111/j.1399-3038.2007.00650.x

32. Rusconi F, Gagliardi L, Galassi C, Forastiere F, Brunetti L et al (2011) Paracetamol and antibiotics in childhood and subsequent development of wheezing/asthma: association or causation? Int J Epidemiol 40(3):662-667. doi:10.1093/ije/dyq263

33. Castro-Rodriguez JA, Garcia-Marcos L, Alfonseda Rojas JD, Valverde-Molina J, Sanchez-Solis M (2008) Mediterranean diet as a protective factor for wheezing in preschool children. J Pediatr 152(6):823-828. doi:10.1016/j.jpeds.2008.01.003

34. Wjst M, Hoelscher B, Frye C, Wichmann HE, Dold S et al (2001) Early antibiotic treatment and later asthma. Eur J Med Res 6 (6):263-271

35. Martel MJ, Rey E, Malo JL, Perreault S, Beauchesne MF et al (2009) Determinants of the incidence of childhood asthma: a twostage case-control study. Am J Epidemiol 169(2):195-205. doi:10.1093/aje/kwn309

36. Thomas M, Custovic A, Woodcock A, Morris J, Simpson A et al (2006) Atopic wheezing and early life antibiotic exposure: a nested case-control study. Pediatr Allergy Immunol 17(3):184 188. doi:10.1111/j.1399-3038.2006.00389.x

37. Kozyrskyj AL, Ernst P, Becker AB (2007) Increased risk of childhood asthma from antibiotic use in early life. Chest 131 (6):1753-1759. doi:10.1378/chest.06-3008

38. McKeever TM, Lewis SA, Smith C, Collins J, Heatlie H et al (2002) Early exposure to infections and antibiotics and the incidence of allergic disease: a birth cohort study with the West Midlands General Practice Research Database. J Allergy Clin Immunol 109(1):43-50

39. Cullinan P, Harris J, Mills P, Moffat S, White C et al (2004) Early prescriptions of antibiotics and the risk of allergic disease in adults: a cohort study. Thorax 59(1):11-15

40. Almqvist C, Wettermark B, Hedlin G, Ye W, Lundholm C (2012) Antibiotics and asthma medication in a large register-based cohort study - confounding, cause and effect. Clin Exp Allergy 42 (1):104-111. doi:10.1111/j.1365-2222.2011.03850.x

41. Alm B, Erdes L, Mollborg P, Pettersson R, Norvenius SG et al (2008) Neonatal antibiotic treatment is a risk factor for early wheezing. Pediatrics 121(4):697-702. doi:10.1542/peds.2007-1232

42. Risnes KR, Belanger K, Murk W, Bracken MB (2011) Antibiotic exposure by 6 months and asthma and allergy at 6 years: findings in a cohort of 1,401 US children. Am J Epidemiol 173(3):310 318. doi:10.1093/aje/kwq400

43. Goksor E, Alm B, Thengilsdottir H, Pettersson R, Aberg N et al (2011) Preschool wheeze - impact of early fish introduction and neonatal antibiotics. Acta Paediatr 100(12):1561-1566. doi:10.1111/j.1651-2227.2011.02411.x

44. Jedrychowski W, Perera F, Maugeri U, Mroz E, Flak E et al (2011) Wheezing and asthma may be enhanced by broad spectrum antibiotics used in early childhood. Concept and results of a pharmacoepidemiology study. J Physiol Pharmacol 62(2):189-195

45. Marra F, Marra CA, Richardson K, Lynd LD, Kozyrskyj A et al (2009) Antibiotic use in children is associated with increased risk of asthma. Pediatrics 123(3):1003-1010. doi:10.1542/ peds.2008-1146

46. Marra F, Marra CA, Richardson K, Lynd LD, Fitzgerald MJ (2011) Antibiotic consumption in children prior to diagnosis of asthma. BMC Pulm Med 11:32. doi:10.1186/1471-2466-11-32

47. Mitchell EA, Robinson E, Black PN, Becroft DM, Clark PM et al (2007) Risk factors for asthma at 3.5 and 7 years of age. Clin Exp Allergy 37(12):1747-1755. doi:10.1111/j.1365-2222.2007.02847.x

48. Kummeling I, Stelma FF, Dagnelie PC, Snijders BE, Penders J et al (2007) Early life exposure to antibiotics and the subsequent development of eczema, wheeze, and allergic sensitization in the first 2 years of life: the KOALA Birth Cohort Study. Pediatrics 119(1):e225-e231. doi:10.1542/peds.2006-0896

49. Kusel MM, de Klerk N, Holt PG, Sly PD (2008) Antibiotic use in the first year of life and risk of atopic disease in early childhood. Clin Exp Allergy 38(12):1921-1928. doi:10.1111/j.13652222.2008.03138.x

50. Celedon JC, Fuhlbrigge A, Rifas-Shiman S, Weiss ST, Finkelstein JA (2004) Antibiotic use in the first year of life and asthma in early childhood. Clin Exp Allergy 34(7):1011-1016. doi:10.1111/j.13652222.2004.01994.x 
51. Mai XM, Kull I, Wickman M, Bergstrom A (2010) Antibiotic use in early life and development of allergic diseases: respiratory infection as the explanation. Clin Exp Allergy 40(8):1230 1237. doi:10.1111/j.1365-2222.2010.03532.x

52. Harris JM, Mills P, White C, Moffat S, Newman Taylor AJ et al (2007) Recorded infections and antibiotics in early life: associations with allergy in UK children and their parents. Thorax 62(7):631637. doi:10.1136/thx.2006.072124

53. Koniman R, Chan YH, Tan TN, Van Bever HP (2007) A matched patient-sibling study on the usage of paracetamol and the subsequent development of allergy and asthma. Pediatr Allergy Immunol 18(2):128-134. doi:10.1111/j.1399-3038.2006.00484.x

54. Rodriguez Martinez C, Sossa M, Goss CH (2008) Factors associated with severe disease in a population of asthmatic children of Bogota, Colombia. J Asthma 45(2):141-147. doi:10.1080/ 02770900701840253

55. Lowe AJ, Carlin JB, Bennett CM, Hosking CS, Allen KJ et al (2010) Paracetamol use in early life and asthma: prospective birth cohort study. Br Med J 341:c4616. doi:10.1136/bmj.c4616

56. Schnabel E, Heinrich J, Group LS (2010) Respiratory tract infections and not paracetamol medication during infancy are associated with asthma development in childhood. J Allergy Clin Immunol 126(5):1071-1073. doi:10.1016/j.jaci.2010.08.023

57. Tapiainen T, Dunder T, Mottonen M, Pokka T, Uhari M (2010) Adolescents with asthma or atopic eczema have more febrile days in early childhood: a possible explanation for the connection between paracetamol and asthma? J Allergy Clin Immunol 125 (3):751-752. doi:10.1016/j.jaci.2009.11.039

58. Shaheen SO, Newson RB, Ring SM, Rose-Zerilli MJ, Holloway JW et al (2010) Prenatal and infant acetaminophen exposure, antioxidant gene polymorphisms, and childhood asthma. J Allergy Clin Immunol 126(6):1141 e1147-1148 e1147. doi:10.1016/ j.jaci.2010.08.047

59. Bakkeheim E, Mowinckel P, Carlsen KH, Haland G, Carlsen KC (2011) Paracetamol in early infancy: the risk of childhood allergy and asthma. Acta Paediatr 100(1):90-96. doi:10.1111/j.16512227.2010.01942.x

60. Amberbir A, Medhin G, Alem A, Britton J, Davey G et al (2011) The role of acetaminophen and geohelminth infection on the incidence of wheeze and eczema: a longitudinal birth-cohort study. Am J Respir Crit Care Med 183(2):165-170. doi:10.1164/rccm.201006-09890C

61. Wickens K, Beasley R, Town I, Epton M, Pattemore P et al (2011) The effects of early and late paracetamol exposure on asthma and atopy: a birth cohort. Clin Exp Allergy 41(3):399 406. doi:10.1111/j.1365-2222.2010.03610.x

62. Strippoli MPF, Spycher BD, Beardsmore CS, Silverman M, Kuehni CE (2009) Paracetamol use and the risk of wheeze: causation or bias? Eur Respir J 34:230s

63. Lesko SM, Mitchell AA (1999) The safety of acetaminophen and ibuprofen among children younger than two years old. Pediatrics 104(4):e39

64. Lesko SM, Louik C, Vezina RM, Mitchell AA (2002) Asthma morbidity after the short-term use of ibuprofen in children. Pediatrics 109(2):E20

65. Penders J, Kummeling I, Thijs C (2011) Infant antibiotic use and wheeze and asthma risk: a systematic review and meta-analysis. Eur Respir J 38(2):295-302. doi:10.1183/09031936.00105010

66. Kummeling I, Thijs C (2008) Reverse causation and confounding-by-indication: do they or do they not explain the association between childhood antibiotic treatment and subsequent development of respiratory illness? Clin Exp Allergy 38 (8):1249-1251. doi:10.1111/j.1365-2222.2008.03047.x

67. Murk W, Risnes KR, Bracken MB (2011) Prenatal or early-life exposure to antibiotics and risk of childhood asthma: a systematic review. Pediatrics 127(6):1125-1138. doi:10.1542/peds.2010-2092
68. Marra F, Lynd L, Coombes M, Richardson K, Legal M et al (2006) Does antibiotic exposure during infancy lead to development of asthma?: a systematic review and metaanalysis. Chest 129(3):610-618. doi:10.1378/chest.129.3.610

69. McBride JT (2011) The association of acetaminophen and asthma prevalence and severity. Pediatrics 128(6):1181-1185. doi:10.1542/ peds.2011-1106

70. Subbarao P, Becker A, Brook JR, Daley D, Mandhane PJ et al (2009) Epidemiology of asthma: risk factors for development. Expert Rev Clin Immunol 5(1):77-95. doi:10.1586/ 1744666X.5.1.77

71. Newson RB, Shaheen SO, Chinn S, Burney PG (2000) Paracetamol sales and atopic disease in children and adults: an ecological analysis. Eur Respir J 16(5):817-823

72. Dimova S, Hoet PH, Dinsdale D, Nemery B (2005) Acetaminophen decreases intracellular glutathione levels and modulates cytokine production in human alveolar macrophages and type II pneumocytes in vitro. Int J Biochem Cell Biol 37(8):1727-1737. doi:10.1016/j.biocel.2005.03.005

73. Scialli AR, Ang R, Breitmeyer J, Royal MA (2010) Childhood asthma and use during pregnancy of acetaminophen. A critical review. Reprod Toxicol 30(4):508-519. doi:10.1016/ j.reprotox.2010.09.005

74. Blanco RA, Ziegler TR, Carlson BA, Cheng PY, Park Y et al (2007) Diurnal variation in glutathione and cysteine redox states in human plasma. Am J Clin Nutr 86(4):1016-1023

75. Shaheen SO (2011) Commentary: Paracetamol and asthmalessons from the antibiotic hypothesis? Int $\mathrm{J}$ Epidemiol 40 (3):667-669

76. Pharmacovigilance Working Party (2011) Monthly report 2011 no. 1102. Available at: http://www.ema.europa.eu/docs/en_GB/ document_library/Report/2011/02/WC500102322.pdf Accessed 4 June 2012

77. Beasley R, Clayton T, Crane J, von Mutius E, Lai CK et al (2008) Association between paracetamol use in infancy and childhood, and risk of asthma, rhinoconjunctivitis, and eczema in children aged 6-7 years: analysis from Phase Three of the ISAAC programme. Lancet 372(9643):1039-1048. doi:10.1016/S01406736(08)61445-2

78. Kwon SJ, Lee CW (1998) Figurate purpuric eruptions on the trunk: acetaminophen-induced rashes. J Dermatol 25(11):756-758

79. Wickens K, Pearce N, Crane J, Beasley R (1999) Antibiotic use in early childhood and the development of asthma. Clin Exp Allergy 29(6):766-771

80. Awasthi S, Kalra E, Roy S (2004) Prevalence and risk factors of asthma and wheeze in school-going children in Lucknow, North India. Indian Pediatr 41(12):1205-1210

81. Cohet C, Cheng S, MacDonald C, Baker M, Foliaki S et al (2004) Infections, medication use, and the prevalence of symptoms of asthma, rhinitis, and eczema in childhood. J Epidemiol Commun Health 58(10):852-857. doi:10.1136/jech.2003.019182

82. Ahn KM, Lee MS, Hong SJ, Lim DH, Ahn YM et al (2005) Fever, use of antibiotics, and acute gastroenteritis during infancy as risk factors for the development of asthma in Korean schoolage children. J Asthma 42(9):745-750. doi:10.1080/ 02770900500308023

83. Floistrup H, Swartz J, Bergstrom A, Alm JS, Scheynius A et al (2006) Allergic disease and sensitization in Steiner school children. J Allergy Clin Immunol 117(1):59-66. doi:10.1016/ j.jaci.2005.09.039

84. Foliaki S, Pearce N, Bjorksten B, Mallol J, Montefort S et al (2009) Antibiotic use in infancy and symptoms of asthma, rhinoconjunctivitis, and eczema in children 6 and 7 years old: International Study of Asthma and Allergies in Childhood Phase III. J Allergy Clin Immunol 124(5):982-989. doi:10.1016/ j.jaci.2009.08.017 
85. Karimi M, Mirzaei M (2009) Antibiotic use and symptoms of asthma, allergic rhinitis, and eczema in children. Iran J Pediatr 19 (2):141-146

86. Mitchell EA, Stewart AW, Clayton T, Asher MI, Ellwood P et al (2009) Cross-sectional survey of risk factors for asthma in 6-7year-old children in New Zealand: International Study of Asthma and Allergy in Childhood Phase Three. J Paediatr Child Health 45 (6):375-383. doi:10.1111/j.1440-1754.2009.01504.x

87. Yeh KW, Ou LS, Yao TC, Chen LC, Lee WI et al (2011) Prevalence and risk factors for early presentation of asthma among preschool children in Taiwan. Asian Pac J Allergy Immunol 29(2):120-126

88. Ponsonby AL, Couper D, Dwyer T, Carmichael A, Kemp A (1999) Relationship between early life respiratory illness, family size over time, and the development of asthma and hay fever: a seven year follow up study. Thorax 54(8):664-669

89. Illi S, von Mutius E, Lau S, Bergmann R, Niggemann B et al (2001) Early childhood infectious diseases and the development of asthma up to school age: a birth cohort study. Br Med J 322 (7283):390-395

90. Celedon JC, Litonjua AA, Ryan L, Weiss ST, Gold DR (2002) Lack of association between antibiotic use in the first year of life and asthma, allergic rhinitis, or eczema at age 5 years. Am J Respir Crit Care Med 166(1):72-75

91. Verhulst SL, Vael C, Beunckens C, Nelen V, Goossens H et al (2008) A longitudinal analysis on the association between antibiotic use, intestinal microflora, and wheezing during the first year of life. J Asthma 45(9):828-832. doi:10.1080/ 02770900802339734

92. Wickens K, Ingham T, Epton M, Pattemore P, Town I et al (2008) The association of early life exposure to antibiotics and the development of asthma, eczema and atopy in a birth cohort: confounding or causality? Clin Exp Allergy 38(8):1318-1324. doi:10.1111/j.1365-2222.2008.03024.x

93. Dom S, Droste JH, Sariachvili MA, Hagendorens MM, Oostveen E et al (2010) Pre- and post-natal exposure to antibiotics and the development of eczema, recurrent wheezing and atopic sensitization in children up to the age of 4 years. Clin Exp Allergy 40(9):1378-1387. doi:10.1111/j.1365-2222.2010.03538.x

94. Su Y, Rothers J, Stern DA, Halonen M, Wright AL (2010) Relation of early antibiotic use to childhood asthma: confounding by indication? Clin Exp Allergy 40(8):1222-1229. doi:10.1111/ j.1365-2222.2010.03539.x

95. Karimi M, Mirzaei M, Ahmadieh MH (2006) Acetaminophen use and the symptoms of asthma, allergic rhinitis and eczema in children. Iran J Allergy Asthma Immunol 5(2):63-67

96. Kuschnir FC, Alves da Cunha AJ (2007) Environmental and socio-demographic factors associated to asthma in adolescents in Rio de Janeiro, Brazil. Pediatr Allergy Immunol 18(2):142148. doi:10.1111/j.1399-3038.2006.00477.x

97. Vlaski E, Stavric K, Isjanovska R, Seckova L, Kimovska M (2007) Acetaminophen intake and risk of asthma, hay fever and eczema in early adolescence. Iran J Allergy Asthma Immunol 6(3):143-149

98. Wong GW, Leung TF, Ma Y, Liu EK, Yung E et al (2007) Symptoms of asthma and atopic disorders in preschool children: prevalence and risk factors. Clin Exp Allergy 37(2):174-179. doi:10.1111/j.1365-2222.2007.02649.x

99. Foliaki S, Annesi-Maesano I, Tuuau-Potoi N, Waqatakirewa L, Cheng $\mathrm{S}$ et al (2008) Risk factors for symptoms of childhood asthma, allergic rhinoconjunctivitis and eczema in the Pacific: an ISAAC Phase III study. Int J Tuberc Lung Dis 12(7):799-806

100. Wang HY, Pizzichini MM, Becker AB, Duncan JM, Ferguson AC et al (2010) Disparate geographic prevalences of asthma, allergic rhinoconjunctivitis and atopic eczema among adolescents in five Canadian cities. Pediatr Allergy Immunol 21(5):867-877. doi:10.1111/j.1399-3038.2010.01064.x

101. Beasley RW, Clayton TO, Crane J, Lai CK, Montefort SR et al (2011) Acetaminophen use and risk of asthma, rhinoconjunctivitis, and eczema in adolescents: International Study of Asthma and Allergies in Childhood Phase Three. Am J Respir Crit Care Med 183(2):171-178. doi:10.1164/rccm.201005-0757OC

102. Gonzalez-Barcala FJ, Pertega S, Castro TP, Sampedro M, Lastres JS et al (2012) Exposure to paracetamol and asthma symptoms. Eur J Public Health. doi:10.1093/eurpub/cks061 